\title{
Dietary Diversity Score: A Measure of Nutritional Adequacy or an Indicator of Healthy Diet?
}

\section{Habte TY ${ }^{*}$ and Krawinkel M}

\author{
Department of International Nutrition, Institute of Human Nutrition, Justus-Liebig-University Giessen, Giessen, \\ Germany
}

*Corresponding author: Habte TY, Department of International Nutrition, Institute of Human Nutrition, Wilhelmstrasse 16a, 35392 Giessen, Germany, E-mail: Tsige-Yohannes.Habte@ernaehrung.uni-giessen.de

Citation: Habte TY, Krawinkel M (2016) Dietary Diversity Score: A Measure of Nutritional Adequacy or an Indicator of Healthy Diet? J Nutr Health Sci 3(3): 303. doi: 10.15744/2393-9060.3.303

Received Date: May 21, 2016 Accepted Date: August 22, 2016 Published Date: August 24, 2016

\begin{abstract}
At the time when the lack of indicators seemed to constrain appropriate child feeding in developing countries, dietary diversity score (DDS) emerged as a measure of nutritional adequacy that could close the gap. DDS refers to the number of food groups consumed in a given time, often in $24 \mathrm{hrs}$. Commonly, a diet of at least 4 DDS was valid as nutritionally adequate. Though validations with the test of correlation between DDS and nutrient adequacy ratio (NAR) or mean nutrient adequacy ratio (MAR) have been highly significant $(\mathrm{p}<0.001)$, the correlation coefficients in most cases were less than 0.5 indicating problems of deficiency. MAR cannot prove itself a true reference of nutrients adequacy because it stands for the mean ratio of all nutrients to recommended allowance of the nutrients, masking the real status of each nutrient. The differences in gender, age and physiology of the participants in the validation of DDS, the variability of nutrient density within food groups, and the neglect of food intake further complicate the accuracy of DDS as a measure of nutrient adequacy. It is true that dietary diversity increases the potential for the provision of different nutrients and healthy phytochemicals that satisfy the requirement for normal growth and health. It also contributes to the ecosystem services by its involvement in primary production, nutrient cycle, food provision and environmental regulation. These favorable characters and the contrasting problems of standardizing DDS as a measure of nutritional adequacy, call for a change that suggest to better use DDS as an indicator of healthy diet.
\end{abstract}

Keywords: Dietary Diversity; Dietary Diversity Score; Nutritional Adequacy; Nutrient Adequacy Ratio (NAR); Mean Adequacy Ratio (MAR); Healthy Diet

\section{Introduction}

Attempts of establishing some association between dietary diversity score and nutritional quality have been known since 1960s, and recoded evidences exist starting early 1980s [1,2]. Several trials are conducted to qualify appropriate feeding practices of the population in developing countries since the Global Consultation on Complementary Feeding convened by WHO identified lack of indicators as one of the constraints of improving young child feeding [3-5]. Consequently, dietary diversity score (DDS) which quantifies the number of food groups in a diet consumed over a reference period emerged as a potential indicator of nutritional adequacy [6].

DDS is differentiated as household dietary diversity score (HDDS) and individual dietary diversity score (IDDS), including child diversity score (CDDS) and women dietary score (WDDS) [7]. HDDS is a proxy measure of the household access to food, or the proxy measure of the socio-economic level of household, whereas the IDDS is a proxy measure of the nutritional quality of individual's diets, particularly that of micronutrient adequacy of a diet [8]. Two to three different arrays of food groups formed the basis for quantifying DDS as indicator of nutritional quality, most often 12 food groups are considered for HDDS and 8 or 9 food groups for IDDS $[6,9,10]$.

The purposes for counting the food groups have varied based on the envisaged target of a project, which can be establishing: a qualitative measure of household-access to a variety of foodstuffs $[11,12]$, an indicator of adequate nutrient intake or a valid measure of nutritional adequacy $[9,13-15]$.

There is some evidence indicating that DDS and nutritional status can both correlate or interact [9]. This inconsistency is attributable to some confounding factors that include location (urban/rural), socioeconomic, demographic, and within foodgroup variability [9]. There has also been the possibility that diagnostic interpretation of the results of correlation lead to wrong conclusion [2,15-17]. 
The variability of nutrient content within each food group could be another source of inconsistency [4,18]. These variations limit the comparison and generalization of findings, which in turn hinder the standardization of DDS as a measure of nutritional adequacy $[11,19]$. Despite the problems of standardization, dietary diversity is still being validated as a measure of nutritional quality by the same old correlation method [12].

The purpose of this analytical study is to diagnose the accuracy of dietary diversity score as a measure of nutritional adequacy and to explain the values of dietary diversity for human health and the sustainability of ecological functions.

\section{Methods}

The details of the problems of DDS as a measure of nutritional adequacy are diagnosed using relevant literature published since 1980s, standard calculation of nutritional adequacy based on the nutrient composition of foodstuffs and the nutrient requirement of different age, sex and physiological status of people and the accumulated nutritional knowledge and relevant experiences. Considerable attention is payed to the differences in the contexts that influence DDS, the challenges of its standardization, the problems of forfeiting the measure of food intake and the interpretation of the results of validation $[18,20]$.

Following the results of the analysis and based on the potential of dietary diversity in providing a variety of nutrients with different concentration, the supply of healthy phytochemicals, and the benefits of agricultural diversity (diversified food production) to the ecosystem, a proposition towards the delineation and delimitation of the purpose of DDS is suggested $[21,22]$.

\section{Brief review of the methods involved in using DDS as a measure of nutrient adequacy}

Dietary diversity score is most often determined by counting the number of selected food groups consumed by a household or individuals over a reference period, which usually ranges between 1-3 days, and in some cases extends to 7 days or even to 15 days $[9,23,24]$. As indicated in Table 1 , the food groups are selected from a given array of recommended food groups, which can be 9 (35), 10 (51) or 12 (37) or other than these.

\begin{tabular}{|c|c|c|c|}
\hline Groups & FAO [6] & Kennedy \& Nantel [9] & $\begin{array}{c}\text { FANTA (Swindale \& } \\
\text { Bilinsky) [10] }\end{array}$ \\
\hline I & $\begin{array}{c}\text { Starchy staples (cereals, } \\
\text { roots, tubers) }\end{array}$ & Cereals, roots and tubers & Cereals \\
\hline II & $\begin{array}{c}\text { Vitamin A rich fruits } \\
\text { and vegetables }\end{array}$ & $\begin{array}{c}\text { Vitamin A rich fruits \& } \\
\text { vegetables }\end{array}$ & Roots/tubers \\
\hline III & Other fruits & Other fruits & Vegetables \\
\hline IV & Other vegetables & Other vegetables & Fruits \\
\hline V & Legumes and nuts & Legume, pulses \& nuts & Meat/poultry/offal \\
\hline VI & Fats and oils & Oils and fats & Eggs \\
\hline VII & Meat, poultry, fish & Meat poultry fish & Fish/sea food \\
\hline VIII & Milk and milk-products & Dairy & Pulses/legumes/nuts \\
\hline IX & Eggs & Eggs & Milk/milk \\
\hline X & & Others (sweets, chips, soda - - & Oil/fats \\
\hline XI & & & Sugar/honey \\
\hline XII & & \multicolumn{2}{|c|}{} \\
\hline
\end{tabular}

The base for the classification of foodstuffs in different groups lies on the variability of nutrient density. Some foodstuffs are relatively rich in energy, others in protein, minerals, or vitamins. The classification of foodstuffs on these bases facilitates the search for substitutes of similar nutrient suppliers. But, this does not presuppose any 1 to 1 substitution in the same group as implicated in the determination of DDS when level of food intake is forfeited. Differences in nutrient density within or between food groups hint the regulation of substitution based on the level of intake (Table 2). If, for example, pulses are supposed to satisfy the average daily Fe requirement ( $15 \mathrm{mg}$ /day) the level of intake needs to be adjusted based on the concentration of the nutrient in the concerned foodstuffs. With the assumption that the bioavailability of iron in the pulses is similar and the supply of Fe in the other components of the diet is negligible, a type of pulse that contains $8 \mathrm{mg}$ Fe $/ 100 \mathrm{~g}$ have to be supplied at the rate of $200 \mathrm{~g} / \mathrm{day}$, whereas $100 \mathrm{~g}$ of that which contains $15 \mathrm{mg} \mathrm{Fe} / 100 \mathrm{~g}$ can satisfy the requirement.

In foodstuffs of plant origin, the concentration of nutrients generally vary not only according to species but also according to the genotypes or varieties (Table 2). Some studies in CIAT that analyzed more than 1000 accessions of common beans (Phaseolus vulgaris) showed that the concentration of iron can range from 3.4 to $8.9 \mathrm{mg} / 100 \mathrm{~g}$ (mean $5.5 \mathrm{mg} / 100 \mathrm{~g}$ ) and that of zinc from 2.1 to $5.4 \mathrm{mg} / 100 \mathrm{~g}$ (mean $3.5 \mathrm{mg} / 100 \mathrm{~g}$ ) [25,26]. There is sufficient genetic variability to increase the iron concentration of common beans by about $80 \%$ and zinc by $50 \%$, which enabled plant breeders to develop bean variety with high concentration of iron (10mg/100g) [25]. Similarly, wheat genotypes in the genus Triticum prove differences that range between 3.4 to $6.8 \mathrm{mg} / 100 \mathrm{~g}$ for iron and $2.14-$ $10.3 \mathrm{mg} / 100 \mathrm{~g}$ for zinc [27]. 


\begin{tabular}{|c|c|c|c|c|}
\hline Nutrient & Cereals & Pulses & Vegetables & Fruits \\
\hline Energy (kcal) & 340 & 403 & 28 & 55 \\
\hline & $(332-357)$ & $(344-498)$ & $(18-43)$ & $(43-62)$ \\
\hline Protein (g) & 10.0 & 20.7 & 1.98 & 0.6 \\
\hline & $(8.7-10.9)$ & $(17-26.2)$ & $(1-3.5)$ & $0.2-1.4$ \\
\hline $\mathbf{C a}(\mathbf{m g})$ & 25.8 & 116.4 & 40.9 & 13.9 \\
\hline & $(7-54)$ & $(51-277)$ & $(10-135)$ & $(5-40)$ \\
\hline $\mathbf{F e}(\mathbf{m g})$ & 2.78 & 9.18 & 0.59 & 0.26 \\
\hline & $(0.8-4.72)$ & $(4.98-15.7)$ & $(0.3-0.86)$ & $(0.1-0)$. \\
\hline $\mathbf{Z n} \mathbf{( m g )}$ & 10.5 & 19.8 & 27 & 2.07 \\
\hline & $(2-35)$ & $(2-58)$ & $(3-69)$ & $(0-16)$ \\
\hline Se (mg) & 23.7 & 9.28 & 0.76 & 0.31 \\
\hline & $(2.8-89.4)$ & $(3.1-17.8)$ & $(0-2.5)$ & $(0-0.6)$ \\
\hline $\boldsymbol{\beta}$ carotene (mcg) & & & 416 & 105 \\
\hline & & & $(15-1430)$ & $(25-310)$ \\
\hline Riboflavin (mg) & 0.14 & 0.18 & 0.08 & \\
\hline & $(0.1-0.22)$ & $(0.16-0.24)$ & $(0.04-0.13)$ & \\
\hline Ascorbic acid (mg) & & & & 34.2 \\
\hline & & & & $(1-74)$ \\
\hline
\end{tabular}

Table 2: Nutrient composition of each $100 \mathrm{~g}$ food group (mean and range) $[4,18]$

The number of food groups in a daily diet of individuals or households are often measured by 24-hour recall. Each participant is required to list all foods and drinks consumed on the previous day without quantifying them. An item consumed from a specific food group is counted only once and DDS of $<4$ represents poor diversity [28]. The number of food groups recommended in different studies are different and the optimal array of food groups for the determination of the DDS as an indicator of nutrient adequacy have not yet been thoroughly explored and standardized $[5,9,11]$.

The correlation of DDS and nutrient adequacy ratio (NAR) or mean adequacy ratio (MAR) are considered in the validation of DDS as the measure of nutritional adequacy. NAR refers to the ratio of the level of a nutrient consumed to recommended nutrient intake (RNI) [29]. Mean adequacy ratio is the sum of NARs of all evaluated nutrients divided by the number of nutrients and expressed in percentage. Conceptually, MAR cannot be a true reference of nutrient adequacy because it represents the average ratio of a lump sum that mixes up all inadequacies, adequacies and even surpluses of different nutrients. In practical sense, the mean of the summation of the ratios ( $\mathrm{NIa} / \mathrm{RNIa}+\mathrm{NIb} / \mathrm{RNIb}+\mathrm{NIc} / \mathrm{RNIc}---) / \mathrm{N})$ can mask the true status of a specific nutrient, because each nutrient has its own level of adequacy. For example, if the nutritional adequacy for iron is $140 \%$ and that of calcium is $60 \%$, MAR will be $100 \%$ reflecting perfect adequacy. The deficiency of calcium is masked by higher level of iron consumption. The number of nutrients commonly considered in the calculation of MAR, which is 11 , can still complicate the matter to an even higher extent.

\section{Validation}

Positive and significant correlations were recorded between DDS and the mean adequacy ratio of nutrients (MAR) (Table 3). Even though dietary diversity score is repeatedly evaluated as acceptable or even good tool for the assessment of the nutritional adequacy, the results in Table 3 are not confirmative because of the weak levels of correlation coefficient. Correlation coefficients in the order of 1.0 is perfect, 0.5 to 0.7 are medium, 0.3 to 0.49 are low and less than 0.3 are little if at all any correlation [30,31].

\begin{tabular}{|c|c|c|c|c|}
\hline Correlates & $\begin{array}{l}\text { Correlation } \\
\text { coefficient }(\mathbf{r})\end{array}$ & Validation & DDS & Sources \\
\hline \multirow[t]{5}{*}{ DDS and MAR } & $\mathrm{r}=0.39, \mathrm{P}<0.001$ & $\begin{array}{l}\text { DDS assess } \mathrm{NA}^{*} \text { fairly } \\
\text { good }\end{array}$ & 6 & Hatloy, et al. 1998 \\
\hline & $\mathrm{r}=0.3, \quad>>>>$ & Not conclusive & 7.8 & Torheim, et al. 2004 \\
\hline & $\mathrm{r}=0.42,>>>>$ & $\begin{array}{l}\text { DDS appropriate } \\
\text { indicator of NIA* }\end{array}$ & 12 & Mirmiran, et al. 2004 \\
\hline & $\mathrm{r}=0.134, \mathrm{P}<0.01$ & No comment & & Sealey-Potts, et al. 2014 \\
\hline & $r=0.65, P<0.001$ & $\begin{array}{c}\text { DDS of } 4 \text { is best } \\
\text { indicator of MAR less } \\
\text { than } 50 \%\end{array}$ & & Steyn, et al. 2006 \\
\hline
\end{tabular}

$\mathrm{NA}^{*}=$ Nutritional adequacy; $\mathrm{NIA}^{*}=$ Nutrient intake adequacy

Table 3: Correlation coefficient between dietary diversity score (DDS) and mean nutrient adequacy ratio (MAR) 
Nutrient or nutritional adequacy literally refers to the fulfillment of daily nutrients requirement by adequate consumption of diverse foodstuffs that form a balanced diet. In this sense adequacy is an indicator of equilibrium between nutrient requirement and intake. The ideal or perfect correlation coefficient for nutrient adequacy is 1 meaning all nutrients consumed can satisfy the recommended allowance or the nutrient requirement [1]. Equality or equilibrium does not have any progressive form. As there is no "more equal or less equal" there is also no "more adequate or less adequate". A diet can be either adequate, deficient or surplus of a nutrient in question. Anything below the recommended level of intake can cause deficiency with or without discernable clinical signs and with potential adverse nutritional and health consequences. A good mineral balance is indispensable for normal growth and health; but deficiency, overdose or imbalance between inorganic nutrients have negative effect on health [32].

As indicated earlier (page 3), the use of MAR to validate DDS as a measure of nutrient adequacy could be misleading because of the masking effect of the different concentration of nutrients and level of intake that can end up in hidden hunger. This could have severe consequences on the wellbeing of human beings. In the earlier years of nutritional studies (at about the beginning of the $20^{\text {th }}$ century), Wilcock and Hopkins fed rats with a mixture of food containing all nutrients they believed to be essential for survival, but the rats died. Later they recognized that the mixture was deficient in the amino acid tryptophan [33]. This proved to be the first practical example that showed the deficiency of a single essential nutrient could invalidated the rough estimation of nutritional quality [34].

Even mild micronutrient deficiency can result in the lack of wellbeing and general fatigue, reduced resistance to infection and low mental processes affecting memory, concentration, attention and mood. In the years as early as the $18^{\text {th }}$ century the renowned chemist Justus von Liebig in his "Low of Minimum" stated that if one nutrient is deficient growth will be restricted [35]. Similarly, if a baby is supplied with all of the nutrients except for one, it strives for few months, after which it will begin to waste away and develop symptoms from which it will ultimately succumb.

In the studies indicated in Table 3 the validations are not consistent probably because of relativism, a range of ideas and positions that may implicate the lack of consensus on how DDS and nutrient adequacy should be defined. The comparison of DDS of different countries have been challenging because of the use of different food groups and scoring systems. Unlike recent studies, older studies have shown significant associations between DDS and nutritional indicators. However, an analysis of the association of dietary diversity and nutritional status in several countries showed both significant correlations and interactions probably because of the confounding effects of socioeconomic factors such as health, education and wealth [24].

A detailed study about the correlation of DDS and nutrient adequacy ratio (NAR) came up with similar results as that of DDS and MAR. The correlation coefficients between DDS and nutrient adequacy ratio in the different studies are variably low indicating its low potential to predict nutrient adequacy (Table 4). The levels of correlation coefficients which are low and widely variable (e.g. for vitamin $\mathrm{A}, \mathrm{r}=0.14-0.43$ ) inflict a considerable challenge to the standardization of DDS as a measure of nutrient adequacy. In none of the studies can DDS prove an overwhelmingly acceptable predictor of nutrients adequacy because the values of all correlation coefficients except for one are below 0.5.

\begin{tabular}{|c|c|c|c|c|c|c|}
\hline Nutrients & $\begin{array}{c}\text { Kennedy, } \\
\text { et al. 2007 }\end{array}$ & $\begin{array}{c}\text { Mirmiran, et } \\
\text { al. 2006 }\end{array}$ & $\begin{array}{c}\text { Steyn, et } \\
\text { al. 2006 }\end{array}$ & $\begin{array}{c}\text { Hatloy, et } \\
\text { al. 1998 }\end{array}$ & $\begin{array}{c}\text { Mirmiral, } \\
\text { et al. 2004 }\end{array}$ & $\begin{array}{c}\text { Sealy-Potts, } \\
\text { et al. 2014 }\end{array}$ \\
\hline Vit. A & 0.43 & 0.32 & 0.19 & 0.3 & 0.26 & 0.136 \\
\hline Vit. C & 0.29 & 0.44 & 0.15 & 0.29 & 0.14 & 0.15 \\
\hline Thiamin & 0.31 & & 0.22 & & 0.05 & 0.08 \\
\hline Riboflavin & 0.4 & 0.44 & 0.36 & & 0.16 & 0.058 \\
\hline Niacin & 0.23 & & 0.49 & & & 0.081 \\
\hline Pyridoxin & 0.13 & 0.22 & 0.48 & & & 0.28 \\
\hline Folate & 0.35 & & 0.29 & & & 0.248 \\
\hline Vit. B12 & 0.06 & 0.24 & 0.13 & & & 0.009 \\
\hline Ca & 0.02 & 0.54 & 0.25 & & 0.35 & 0.001 \\
\hline Zn & 0.1 & 0.24 & 0.4 & & 0.32 & 0.05 \\
\hline Fe & 0.15 & 0.24 & 0.26 & & 0.03 & 0.141 \\
\hline Mg & & & & & 0.29 & \\
\hline
\end{tabular}

Table 4: Correlation coefficient (r) between dietary diversity score and nutrient adequacy ratio (NAR)

Dietary diversity score is considered as a measure of macro- and micronutrients adequacy irrespective of the level of food intake $[7,14,19]$. Some studies, which validated the mean DDS for good, indicated differing micronutrients deficiency for mothers and their children; and low food intake was explained as the cause of the problem [36]. In other studies the combination of both low diversity and low food intake are given as the cause of nutrient inadequacy $[19,37]$.

In a study conducted in Bangladesh, with the daily diet of women consisting of rice, dairy products, eggs, meat, fish, vitamin A rich fruits and vegetables mixed in the proportion that $84 \%$ of the diet consists of rice; more than $97 \%$ of the women were deficient in 
vitamin A and Ca [36]. Low food intake and dietary diversity with DDS (4.2) were mentioned to result in the deficiency problems. In line with this, inadequate micronutrient intake was identified as the major cause for vitamin A, folate, iron and zinc deficiencies among young children and women of childbearing age residing in developing countries $[37,38]$.

A test of nutritional adequacy in Africa based on foodstuffs available for consumption and the nutrient requirement of the population classified according to age, gender, physiological status and physical activity level indicated deficiency, adequacy and surplus status of nutrients for similar number of food groups. (own analysis, Table 5) [39].

\begin{tabular}{|c|c|c|c|c|c|c|c|c|c|c|}
\hline & Cereals & R\&t $^{*}$ & Pulses & Veges. & Fruits & Meat & Fat & Milk & Sugars $^{*}$ & Others \\
\hline Algeria & 625 & 118 & 25 & 326 & 175 & 82 & 41 & 323 & 90 & 22 \\
\hline Egypt & 630 & 79 & 22 & 556 & 274 & 115 & 19 & 170 & 66 & 14 \\
\hline Ethiopia & 397 & 208 & 46 & 36 & 33 & 25 & 5 & 47 & 16 & 49 \\
\hline Kenya & 326 & 129 & 49 & 137 & 148 & 58 & 22 & 268 & 49 & 38 \\
\hline Zimbabwe & 441 & 49 & 33 & 38 & 38 & 63 & 30 & 77 & 77 & 101 \\
\hline S. Africa & 510 & 88 & 16 & 99 & 93 & 175 & 41 & 159 & 85 & 189 \\
\hline Cameroon & 310 & 359 & 55 & 200 & 230 & 46 & 22 & 36 & 30 & 134 \\
\hline Ghana & 264 & 1036 & 41 & 99 & 400 & 120 & 27 & 22 & 33 & 66 \\
\hline
\end{tabular}

Cereals form the major component of the diet in North, East and South Africa. In North Africa wheat is the major (70\%) cereal, and coarse cereals (20\%) are secondary. In East and South Africa coarse cereals (maize, sorghum, millet) are predominant (66\%), and maize accounts for about $60 \%$ of the coarse cereals. Roots and tubers are the major staple food ingredients in West Africa. Cassava and yam make about $90 \%$ of the root and tubers in Ghana; cassava is only $64 \%$ of the roots and tubers in Cameroonian diet, the rest consists of potatoes, sweet potatoes and yam. Rice is an important complement in the diets of West Africa, Egypt and South Africa.

The pulses mainly consist of dry legumes, oil seeds and tree nuts in different proportions. In North Africa the proportions range between 78\% legumes, 13\% oil seeds and 9\% tree nuts; in East Africa, South Africa and Ghana they consist of 90\%: 6\%: 4\%; 46\% : 50\%: 4\%; and 5\%: 88\%: 7\% respectively. Such variabilities within food groups could inflict considerable differences in nutrient consumption because of differences in nutrient concentration (Table 2).

The level of food consumption is highly variable ranging between $852 \mathrm{~g} / \mathrm{capita} /$ day $(1914 \mathrm{kcal} / \mathrm{capita} /$ day) in Ethiopia to more than $2000 \mathrm{~g} / \mathrm{capita} /$ day (3000kcal/capita/day) in Egypt and Ghana (Table 6). The global average for the years 2000 - 2015 is estimated at $2803-2940 \mathrm{kcal} / \mathrm{capita} /$ day; with an average of $2681 \mathrm{kcal}$ for developing countries and $3380 \mathrm{kcal}$ for industrial countries [41].

\begin{tabular}{|c|c|c|c|}
\hline \multirow[t]{2}{*}{ Country } & \multicolumn{2}{|c|}{ Apparent food intake } & \multirow{2}{*}{$\begin{array}{c}\text { Dietary energy } \\
\mathrm{kcal} / \mathrm{kg}\end{array}$} \\
\hline & g/capita/day & kcal/capita/day & \\
\hline Algeria & 1827 & 3491 & 1911 \\
\hline Egypt & 2059 & 3369 & 1636 \\
\hline Ethiopia & 852 & 1914 & 2246 \\
\hline Kenya & 1294 & 2253 & 1741 \\
\hline Zimbabwe & 946 & 2304 & 2436 \\
\hline S. Africa & 1454 & 2858 & 1965 \\
\hline Cameroon & 1489 & 2457 & 1650 \\
\hline Ghana & 2140 & 3522 & 1645 \\
\hline Mean & 1508 & 2771 & 1904 \\
\hline
\end{tabular}

In terms of gravimeter, North Africa and Ghana excel the average daily per capita food consumption by about $30 \%$, while that of East Africa underlies by $-30 \%$. An analysis of nutritional adequacy in each nation showed that Egypt and Ghana are exposed to over nutrition; but underweight coexists with overweight because of unequal access to food [42]. Even though the DDS in all countries is similar at minimum 6 points, all of the diets are deficient in calcium probably because of low levels of pulses, vegetables, milk and milk products. In East Africa, the diets are deficient in vitamin A, riboflavin, folic acid, vitamin $\mathrm{C}$, calcium and iron because of low availability of foodstuffs and the predominance of staple foods [39].

As the foodstuffs of plant origin differ in their nutrient concentration, it is vital to maintain the proportion of staples, pulses and vegetables at the level where they satisfy the micronutrient requirements. Table 5 reveals the consumption of low level mineral rich 
pulses or legumes (36g/capita/day) in all countries. Even if the optimum level of food groups to include in the daily diet is yet to be set, some $100 \mathrm{~g}$ of pulses is recommended to cover half of the daily iron requirement and at least $400 \mathrm{~g} /$ day of vegetables and fruits is recommended as the component of healthy diet [42].

In general, the study exemplifies how the variability within a food group both in quality and quantity as well as the differences in the level of intake of the same food group and that of total consumption of a diet can limit DDS as a measure of nutrition adequacy.

\section{Nutritional concepts and dietary diversity}

Adequate supply of all nutrients is of paramount importance to satisfy the nutritional requirements of human beings for body maintenance, growth, strength, physical work, cognitive ability, immunity and good health. During early life, the growth and development of the body as well as its maintenance are dependent on correct supply of all essential nutrients. In later life or during maturity, when development and growth are complete, the body requires food mainly for the purpose of work, body maintenance and repair. Mistakes made during the growth period can be permanent and irreversible. In reference to current global nutritional status, about one third of the population of all age and gender groups suffer from the deficiencies of micronutrients, particularly that of iron, zinc, iodine, selenium, and vitamin A [43]

Recent developments show that it is not only inadequate supply of nutrients that cause nutritional problems but also their excessive consumption, which lead to the accumulation of body fat, overweight, obesity, and associated major global health challenges. In 2013, the worldwide prevalence of overweight and obesity increased to $36.9 \%$ in men and $38 \%$ in women; in the developed countries the prevalence of overweight and obesity among children and adolescences was $23.8 \%$ for boys and $22.6 \%$ for girls [17]. According to the same sources, overweight and obesity caused 3.4 million deaths in 2010 worldwide. In this regard, the adverse effects of overdose and deficiency of nutrients, problems of food adulteration and food safety as well as the level of consumption of food, which is predominantly dependent on food availability, accessibility and utilization, occupy central position in the principles of nutrition $[44,45]$.

Metabolic energy generators such as soluble carbohydrates, fats and proteins, when consumed in excess amount, cause overweight and obesity with subsequent health problems. Similarly, excessive intake of vitamins and minerals can influence human wellbeing and health. In order to control over-consumption of micronutrients, guidelines that limit the upper cutoff points are established [46]. There is always the possibility of health problems due to nutrient deficiency, overconsumption, interactions and contamination [47].

Nutrients are contained in foodstuffs in different contexts, structures and levels that form the organizational and functional components of edible plants. There is always a marked variability in the concentration of nutrients and biologically active ingredients in foodstuffs of plant origin. This suggests that only a mixed supply at recommended level can satisfy the nutrient requirements of all age and gender groups of human beings. However, since the beginning of the $20^{\text {th }}$ century, $75 \%$ of plant genetic diversity has been lost as farmers worldwide ignore multiple of local varieties and landraces in order to plant genetically improved uniform and high-yielding varieties, leaving a large proportion (about 75\%) of the world food to be generated from only 12 plant and 5 animal species [48].

At about the middle of the $20^{\text {th }}$ century, food production system started to change in order to promote food availability and hinder the looming hunger. The results at that time were so attractive that the practice eventually expanded to an extent that large areas of natural vegetation are cleared to produce excessive amount of cereals and soybean. The availability of surplus cereals and soybean in some regions enhanced the idea of value added chain when the surplus food items are converted to meat and processed market food. Due to homogenization and intensification of agriculture the global food diversity declines and the consumption of processed food and meat increases, with a dramatic increase in diet-related diseases, in spiraling incidents of diabetes and heart diseases that become epidemic [49].

The loss of food diversity is also closely associated with the destruction of biodiversity worldwide. Only few selected varieties have been multiplied to dominate the world food resources. Extensive areas of land all over the world are cleared from natural vegetation for purposes of homogenous and intensive agricultural practices. Life influencing functions of biodiversity are distracted. The synthesis of nutrients from natural resources, the production of food, fiber and bioenergy, the maintenance of nutrient cycle, and the regulation of the sustainable use of soil, water, the atmosphere and climate are negatively affected due to the loss of biodiversity and its subset dietary diversity. In view of these extended roles and values, dietary diversity appears to be a broader concept than just an aspect of nutrition that inconclusively take care of nutritional adequacy.

According to the current stand of knowledge, biodiversity particularly plant biodiversity can provide sources of both nutrients and medical agents that contribute to sociocultural well-being [50]. The consumption of diverse recommended foodstuffs resulted in the decline of human mortality [51]. Dietary diversity is associated to longevity and reduced degenerative diseases such as cardiovascular diseases, diabetes and cancer [52]. Increased varieties of vegetables and fruits in the diet were associated with reduced incidence of stomach cancer [53]. Dietary diversity with the inclusion of traditional leafy vegetables proved to have antiparasitic effect, antioxidant activity, anti-diabetic remedy and remedies for gout [54-56]. 


\section{Conclusion}

The variability of nutrient concentration within food groups, and the complex influence of sociodemographic, economic, environmental and technological characteristics hinder dietary diversity score as a standard measure of nutritional adequacy.

The correlation coefficients between DDS and NAR or MAR though highly significant, are lower than 0.5; and MAR is by any standard of measure an erroneous evaluator of DDS.

DDS, which considers only the number of food groups consumed over given time, and that which disregards food intake, could not prove a true measure of nutritional adequacy.

Dietary diversity indisputably increases the potential for the provision of diverse nutrients and healthy phytochemicals. It also contributes to the ecosystem services by its involvement in primary production, nutrient cycle, food provision and environmental regulation (water purification, waste treatment, climate regulation, disease control).

In view of its favorable purposes and contrasting problems of using DDS as a measure nutritional adequacy, it is suggested to use dietary diversity score as an indicator of healthy food with ecological benefit.

Dietary diversity consisting among others of food groups classified as sources of energy (cereals, tubers, roots), protein providers (pulses, solid food of animal origin), mineral suppliers (pulses, other legumes, vegetables, solid food of animal origin, milk), and vitamin sources (vegetables, green vegetables, fruits, solid food of animal origin) can be recommended as the indicator of healthy diet. Since the number of food groups involved in the above stated functions is four, it is rational to use this as the minimum cutoff point for healthy diet.

\section{References}

1. Daniel MC (2006) Dietary Diversity as a Measure of Nutritional Adequacy throughout Childhood. PhD Thesis, Department of Nutrition. University of North Carolna, Chapel Hill, United States, 1-143.

2. Guthrie HA, Sheer JC (1981) Validity of dietary score for assessing nutrient adequacy. J Am Diet Assoc 78: 240-5.

3. WHO (2002) World Health Report 2002. World Health Organization, Geneva.

4. Xu Y, An D, Li H, Xu H (2001) Review: Breeding wheat for enhanced micronutrients. Can J Plant Sci 91: 231-7.

5. Ng M, Fleming T, Robinson M, Thomson B, Graetz N, et al. (2014) Global regional and national prevalence of overweight and obesity in children and adults during 1980 - 2013: a systematic analysis for the global Burden of Disease Study 2013. Lancet 384: 766-81.

6. Food and Agriculture Organization of the United Nations (2007) Developing food-based dietary guidelines: a manual from the English speaking Caribbean. Rome 1-85.

7. Food and Nutrition Technical Assistance (2006) Developing and Validating Simple Indicators of Dietary Quality and Energy Intake of Infants and Young Children in Developing Countries: Summary of findings from analysis of 10 data sets. Working Group on Infant and Young Child Feeding Indicators, Academy for Educational Development (AED), Washington, DC, United States 1-112.

8. La Vicchia C, Altieri A, Tavani A (2001) Vegetables, fruits, antioxidants and cancer: a review of Italian studies. Eur J Nutr 40: 261-7.

9. Kennedy GL, Pedro MR, Seghieri C, Nantel G, Brouwer I (2007) Dietary diversity score is a useful indicator of micronutrient intake in non-breast-feeding Filipino children. J Nutr 137: 472-7.

10. USDA: Food Composition Database. Nutrition Facts.

11. Kennedy G, Ballard T, Dop MC (2011) Guidelines for measuring household and individual dietary diversity. Agriculture and Consumer Protection, FAO, Rome.

12. Hatloy A, Halland J, Diara MM, Oshaug A (2000) Food variety socioeconomic status and nutritional status in urban and rural areas in Koutiala (Mali). Public Health Nutr 3: 57-65.

13. Krebs -Smith SM, Smiciklas-Wright H, Guthrie HA and Krebs- Smith J (1987) The effect of variety in food choices on dietary quality. J Am Diet Assoc 87: 897-903.

14. Hatloy A, Torheim LE and Oshang A (1998) Food variety a good indicator of nutritional adequacy of the diet? A case study from an urban area in Mali, West Africa. Eur J Clinl Nutr 52: 891-8.

15. Moursi MM, Arimond M, Dewey KG, Treche S, Ruel MT, et al. (2008) Dietary Diversity is a Good Predictor of the Micronutrient Density of the diet of 6-to 23-Month-Old Children in Madagascar. J Nutr 138: 2448-53.

16. SCF (2006) Tolerable Upper Intake Levels for Vitamins and Minerals. European Food Safety Authority 1-482.

17. Swindale A, Bilisky P (2006) Household Dietary Diversity Score (HDDS) for Measurement of Household Food Access: Indicator Guide. Version 2, FANTA, Connecticut Ave., NW, Washington DC, United States 1-15.

18. FAO (1966) Food Composition Table for Use in Africa. Agriculture and Consumer Protection.

19. Sealey-Potts C, Potts AC (2014) An assessment of Dietary Diversity and Nutritional Status of Pre-school Children. Austin J Nutri Food Sci 2: 1040.

20. FAO \& WHO (2001) Human vitamin and mineral requirements. Report of a joint FAO/WHO Expert Consultation, Food and Agriculture Organization of the United Nations Bangkok, Thailand 1-303.

21. FAO (1999) Women: users, preservers and managers of agrobiodiversity. Economic and Social Development Department.

22. Foote JA, Murphy SP, Wilkens LR, Basiotis PP, Carlson A (2004) Dietary variety increases the probability of nutrient adequacy among adults. J Nutr 134: 177985 . 
23. Hoddinott J, Yohannes Y (2002) Dietary diversity as a food security indicator. FANTA, Washington DC, United States 1-50.

24. Arimond M, Ruel MT (2004) Dietary Diversity is Associated with Child Nutritional Status: Evidence from 11 Demographic and Health Surveys. J Nutr 134: 2579-85.

25. Beebe S, Gonzalez VA, Rengifo J (2000) Research in trace minerals in common beans. Food Nutr Bull 21: 387 -91.

26. Peters JC (1991) Tryptophan Nutrition and Metabolism: An Overview. Adv Exp Med Biol 294: 345-58.

27. Kennedy G, Nantel G (2006) Basic Guidelines for Validation of a Simple Diversity Score as an Indicator of Nutrient Adequacy for Non-Breast Feeding Children 2-6 Years. Nutrition Planning, Assessment and Evaluation Services. Nutrition and Consumer Protection Division, Mexico.

28. Drewnowski A, Henderson SA, Driscoll A, Rolls BJ (1997) The dietary Variety Score: assessing diet quality in healthy young and older adults. J Am Diet Assoc 97: 266-71.

29. Food and Agriculture Organization of the United Nations (2011) Guidelines for measuring household and individual dietary diversity. Rome 1-60.

30. Calkins GK (2005) Applied Statistics - Correlation Coefficients. Berrien Springs, MI 49103 - 0140. Andrews University, United states.

31. Cohen J (1988) Statistical power analysis for the behavioral science ( $2^{\text {nd }}$ edn), Lawrence Erlbaum Associate, Publishers, New York University, New York, United States.

32. Arsenault JE, Yakes EA, Islam MM, Hussain MB, Ahmed T (2013) Very Low of Micronutrient Intakes by Young Children and Women in Rural Bangladesh is Primarily Explained by Low Food Intake and Limited Diversity. J Nutr 143: 197-203.

33. Black RE, Allen LH, Bhutta ZA, Caulfield LE, de Onis M, et al. (2008) Maternal and Child Undernutrition: global and regional exposures and health consequences. Lancet 371: 243-60.

34. Mertz W (1981) The essential trace elements. Science 213: 1332-8.

35. Mirmiran, P, Azadbakht L, Esmaillzadeh A, Azizi F (2004) Dietary diversity score in adolescents- a good indicator of the nutritional adequacy of diets: Tehran lipid and glucose study. Asia Pac J Clin Nutr 13: 56-60.

36. Arimond M, Weismann D, Becquey E, Carriquiry A, Daniels M, et al. (2010) Simple food group diversity indicators predict micronutrient adequacy of women's diets in 5 diverse, resource-poor settings. J Nutr 140: 2059s-69s.

37. Zainal Badari SA, Arcot J, Harbon SA, Paim L, Sulaiman N, et al. (2012) Food variety and dietary diversity score to understand the food-intake pattern among selected Malaysian households. Ecol Food Nutr 51: 265-99.

38. Ogle BM, Hung PH, Tuyet HT (2001) Significance of wild vegetables in micronutrient intake of women in Vietnam: an analysis of food variety. Asia Pac J Clin Nutr 10: 21-30.

39. Petry N, Boy E, Wirth JP, Hurrell RF (2015) Review: The Potential of Common Bean (Phaseolus vulgaris) as a vehicle for Iron biofortification. Nutrients 7: 1144-73.

40. WHO (1998) Complementary feeding of young children in developing countries: A review of current scientific knowledge, Geneva 1-228.

41. Gregorio GB (2002) Progress in Breeding for Trace Minerals in Staple Crops. J Nutr 132: 500S-2S.

42. Ruel MT (2003) Operationalizing dietary diversity: a review of measurement issues and research properties. J Nutr 11: 3911S-26S.

43. Ghandilyan A, Vreugdenhil D, Aarts MGM (2006) Progress in the genetic understanding of plant iron and zinc nutrition. Physiol Plant 126: $407-17$.

44. Habte TY, Krawinkel M (2012) Nutritional adequacy in Africa: The bases for Planning Sustainable and Diverse Food Supply. Abstract: Tropentag, Resilience of agricultural systems against crises. University of Giessen, Germany.

45. Pritchard E (1928) The General Principles of Nutrition. Postgrad Med J 3: 67-9.

46. Agudo A (2005) Measuring intake of Fruits and Vegetables. Background paper for the joint FAO/WHO Workshop on Fruits and Vegetables for Health, Kobe, Japan 1-40.

47. Nielsen FH (1988) Nutritional Significance of the ultra-trace elements. Nutr Rev 46: 337-41.

48. Dolan LC, Matulka RA, Burdock GA (2010) Naturally Occurring Food Toxins. Toxins 2: 2289-332.

49. Styen NP, Nel JH, Nantel G, Kennedy GL, Labadorios D (2006) Food variety and dietary diversity scores in children: are they good indicators of dietary adequacy? Public Health Nutr 9: 644-50.

50. Savy M, Martin-Prevel Y, Swadogo P, Kameli Y, Delpeuch F (2005) Use of dietary variety/diversity scores for diet quality measurement: relations with nutritional status of women in a rural area in Burkina Faso. Eur J Clin Nut 59: 703-16.

51. Ruel M, Graham J, Murphy S, Allen L (2004) Validating simple indicators of dietary diversity and animal source food intake that accurately reflect nutrient adequacy in developing countries. Report submitted to GL-CRSP.

52. Khoury CK, Bjokman AD, Dempewolf H, Ramirez-Villegas J, Guarino L, et al. (2014) Increasing homogeneity in global food supplies and the implications for food security. PNAS 111: 4001-6.

53. Byers T, Nestle M, McTiernan, Doyle C, Currie-Williams A, et al. (2002) American Cancer Society guidelines on nutrition and physical activity for cancer prevention: Reducing the risk of cancer with healthy food choices and physical activity. CA Cancer J Clin 52: 92-119.

54. Kant KA, Schatzkin A, Graubard BI, Schairer C (2000) A Prospective Study of Diet Quality and Mortality in Women. JAMA 283: $2109-15$.

55. Kant KA (1996) Indexes of Overall Diet quality: A Review. J Am Diet Assoc 96: 785-91.

56. Löwik MR, Hulshof KF, Brussaard JH (1999) Food-based dietary guidelines: some assumptions tested for The Netherlands. Br J Nutr 81: S143-9. 


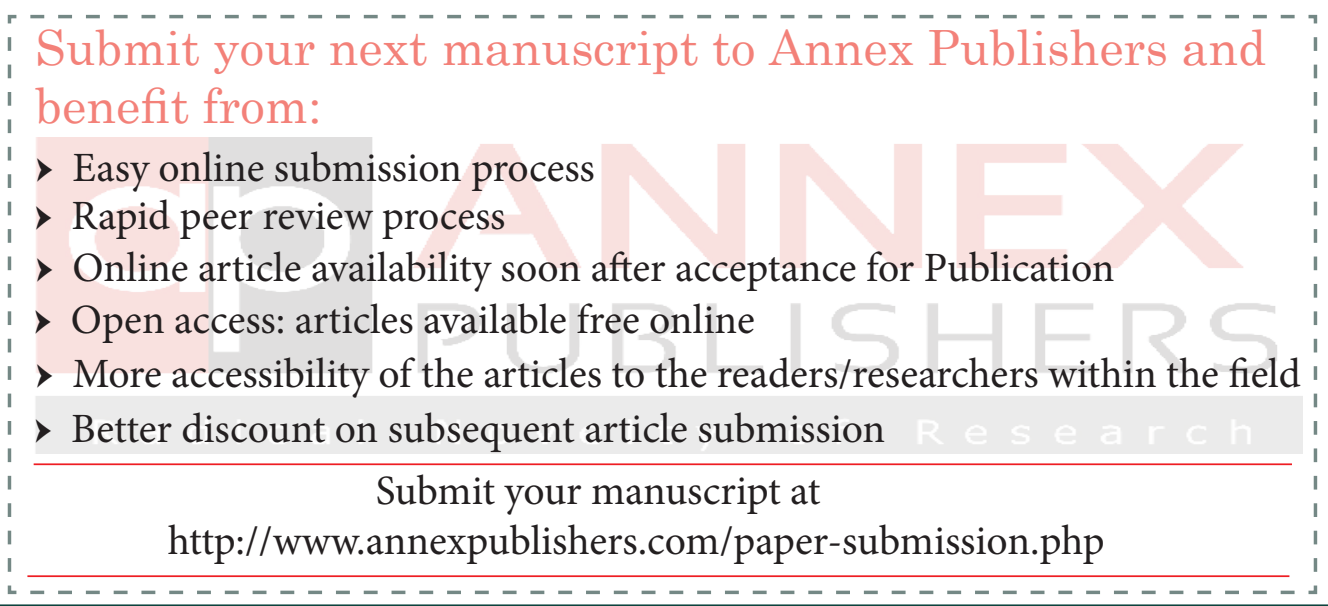

